\title{
Issues limiting the evaluation of post implemented enterprise architecture
}

\author{
Babak Darvish Rouhani ${ }^{1}$, Fatemeh Nikpay ${ }^{2}$, Rodina Binti Ahmad ${ }^{3}$ \\ ${ }^{1,2}$ Department of Computer Engineering and Information Technology, Payame Noor University, Iran \\ ${ }^{2}$ Faculty of Computer Science \& Information Technology, University of Malaya, Malaysia
}

\section{Article Info \\ Article history: \\ Received Dec 23, 2018 \\ Revised Mar 17, 2019 \\ Accepted Jun 28, 2019 \\ Keywords: \\ Enterprise architecture \\ Evaluation \\ Evaluation models \\ Information system \\ Post implementation}

\begin{abstract}
Evaluation in enterprise architecture (EA) project is crucial to provide comprehensive information of the developed EA artefacts. It may assist in accurate evaluation of implemented Information Systems (ISs) in order to realize the achievement of EA's goals and support EA decision makers. This research aims to identify and elaborate the existing issues of EA evaluation models. One of the crucial identified issues is to understand, capture and represent core aspects of EA artefacts. Most existing evaluation models do not provide structured approach which cover comprehensive aspect of EA implementation and some do not provide good practices to be applied. Hence, this research intends to cover the gap by exploring critical issues in EA implementation evaluation and elaborating main shortcomings of the reviewed EA models and methods through a systematic literature review.
\end{abstract}

Copyright $($ C 2019 Institute of Advanced Engineering and Science. All rights reserved.

\section{Corresponding Author:}

Babak Darvish Rouhani,

Department of Computer Engineering and Information Technology,

Payame Noor University, Tehran, I.R.Iran.

Email: darvishrouhani@ pnu.ac.ir

\section{INTRODUCTION}

Enterprise Architecture (EA) provides a comprehensive strategy and environment for aligning enterprise business and Information Technology (IT) [1,2]. In order to provide an appropriate environment for alignment between business and IT, EA describes the current architecture (As-Is), elaborates the desired architecture (To-Be), and represents the migration plan for transition from current architecture to desired architecture for the enterprise [3, 4]. Four architectural levels business, data, application, and infrastructure need to be described in these three aforementioned stages of an EA project [5-7].

EA project comprises a set of developed EA artefacts including the related information systems, documents and enterprise's roadmaps in accordance with the defined EA project objectives. In othis regards, the integration among and between developed information systems are important [8]. This integration provides the appropriate environment for better connectivity of enterprise's business $[9,10]$.

EA evaluation is defined as the process of determining the merit, worth, and value of EA artefacts $[11,12]$. A discipline of evaluation in EA is needed because enterprises as well as EA practitioners in general require systematic, unbiased means of knowing if their products, practices, methods, and EA artefacts met their goals $[11,13,14]$. Evaluation leads to generate information that assist in making judgments and decisions program, service, policy, IS integration, and then to inform decision making to guide practical actions [11, 15-17].

EA evaluation enables the EA project's stakeholders and enterprise architects to evaluate the developed EA artefacts and implemented ISs based on predetermined EA objectives [16]. Employing structured, usable, and effective EA evaluation model becomes vital in each EA project due to the outcome of the project. The common features which are provided by EA evaluation model are as follows: 
1. Investigating the integration of developed ISs

2. Investigating the IT and business alignment in developed EA artefacts

3. Assessing achievement of predetermined EA objectives

4. Assessing the performance of developed EA artefacts in response of EA objectives

5. Assessing the effectiveness of developed EA artefacts with future changes

6. Assessing the functionality of developed EA artefacts

Aforementioned features of EA evaluation models and considering the importance of understanding the situation of implemented EA and achievement of EA objectives for project's investors or stakeholders provide strong basis for the urgent need for effective EA evaluation model. The aim of this research is to further enhancing the development of effective EA evaluation model by initially identifying crucial issues or problems of existing EA evaluation models $[18,19]$.

There are some researches in the area of EA evaluation, however they did not consider postimplemented issues, and provide list of shortcomings. The goal of this research is to investigate the main shortcomings of the post-implemented EA evaluation models and approaches.

The remainder of this paper is divided into the following parts:; the sresearch method of this research in described in Section 2; the current problems of existing EA evaluation models are presented in Section 3; the discussion and conclusion are given in Section 4, and 5 respectively.

\section{RESEARCH METHOD}

This study employed the Systematic Literature Review (SLR) based on the provided guidelines that was proposed by Kitchenham and Charters (2007) in order to conduct the review [18] on finding issues of existing EA evaluation models. Hence, the main research question is: What are the main issues or problems in existing EA evaluation models?

In total, 418 papers were identified and retrieved from 6 reliable databases, including: IEEE, ACM, Springer, Science Direct, Taylor and Francis, and Scholars. The Figure 1 and Figure 2 synthesize the result of the SLR.

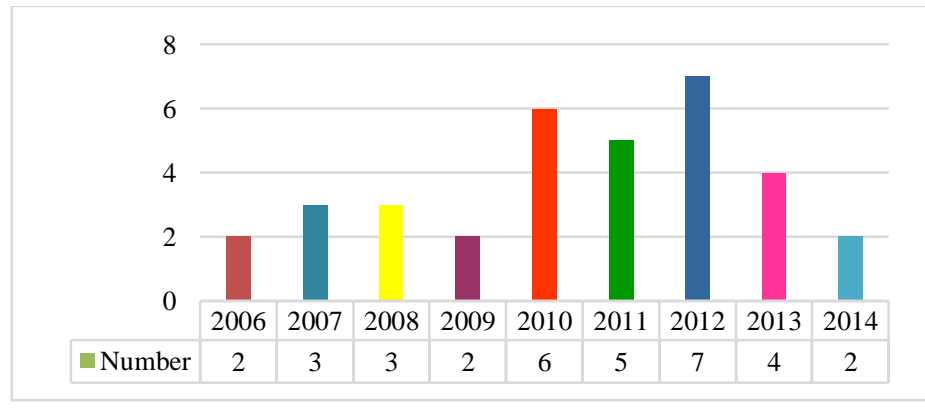

Figure 1. Number of studies by year of publication

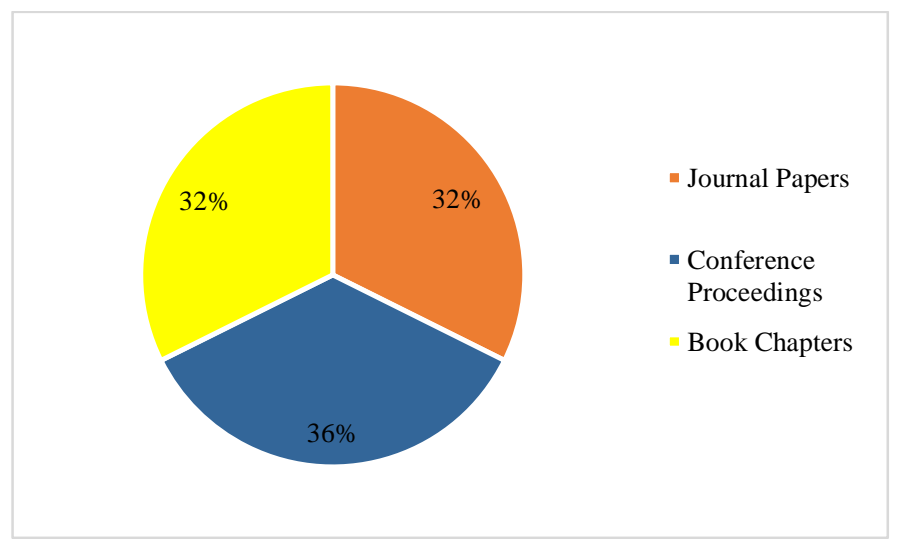

Figure 2. Numbers of selected studies per study type 


\section{ISSUES EXISTING EA EVALUATION MODELS}

Main issues which are identified and summarized are explained as follows:

\subsection{Lack of structured EA Evaluation Model}

Most reviewed models are not based on any sound theoretical basis to provide the holistic understanding of EA evaluation and most do not provide structured mechanisms to evaluate the implemented EA. Moreover, most appraised evaluation models assume that the developed EA artefacts situations are well-defined with established business units and identifiable users who have well-defined roles and positions within the enterprise. The models are mainly developed based on the users' experiences from previous projects and there is no theoretical foundation behind them. The EA evaluation models are frequently inapplicable in situations that may not have well-defined alignment between enterprise IT and business $[11,19,20]$.

\subsection{Lack of a guided method for EA evaluation}

Since the process of evaluation or analysis the EA artefacts within an enterprise is critical for the success of EA implementation, the process should be supported by an effective and useful method to facilitate the EA projects evaluation process. Most of the reviewed evaluation models do not provide the step by step guidance of the EA evaluation process. Employing an appropriate method for implementing the EA evaluation process will tremendously contribute to preventing users' interpretation on the evaluation processes and activities [7,21].

\subsection{Complexities in EA evaluation models employment}

Most studied models do not provide easy to learn and simple practices for evaluating EA implementation. The typical usage of evaluation models in the EA implementation is to increase human understanding in complex matters such as the effectiveness of implemented EA artefacts and the achievement of defined EA objectives. In the context of EA implementation, stakeholders need to consider comprehensively the implemented artefacts of EA and competitive external environments to ensure a full understanding of enterprise situation. Existing EA evaluation models mostly present too detailed, which are time consuming and expensive practices, or too abstract which are not applicable in EA project. Besides, they introduce the main structures and concepts of evaluation in high perspective and do not provide holistic and appropriate metric for evaluation. Therefore, the evaluation faces many difficulties in terms of using the metrics, learning the practices, and implementing the practices [22-24].

\subsection{Lack of a comprehensive EA evaluation model that covers all aspects of EA implementation}

Rapid changing enterprise requirements are the norm currently. Hence, there is a need to focus not only on the present requirements but also the requirements of the immediate future. This is not catered for in most of the reviewed models. The scope of requirements should not only focus on the main operational activities of the enterprise but should also cover the managerial activities [11, 25]. A wider scope of analysis that includes all the essential activities of the enterprise such as planning and coordinating, will enhance the enterprise planning capability in identifying an extensive variety of IS applications that can instigate and sustain the enterprise successfully. This has to be reflected in models for EA evaluation particularly in identifying and relating the requirements of the enterprise to its ISs and information requirements. Existing models seem to stress on identifying cost and benefit of developed EA artefacts. Very few models continue to identify further information and data requirements for the EA evaluation which will be very beneficial to bridge the semantic gap from the business requirements to IT capabilities and developed EA artefacts $[19,26,27]$.

The conclusion that can be made from the reviewed models is that they are mainly deficient in the ability to provide comprehensive useful functionality and make use of the developed EA artefacts effectively. Moreover, it lacks the ability to relate the business requirements to IT capabilities and specifically provide structured approach to facilitate further future changes analysis. Very few EA evaluation models offer comprehensive approach for evaluating all aspects of EA implementation. Table 1 shows the summary of the analysis made and highlights the analyzed features of each model. Subsequently, this research is directed towards addressing such deficiencies. It intends to develop an approach for EA evaluation approach for covering all aspects of implemented EA artefacts. The approach will be equipped with the mechanism to focus on the assessment of functionality and effectiveness of the EA artefacts. 
Table 1. Summary of the Issues in the Studied Evaluation Models

\begin{tabular}{|c|c|c|c|c|}
\hline Evaluation models & $\begin{array}{c}\text { Not covering } \\
\text { all aspects of } \\
\text { EA }\end{array}$ & $\begin{array}{c}\text { Lack of } \\
\text { structured } \\
\text { models }\end{array}$ & $\begin{array}{c}\text { Difficulties } \\
\text { in EA } \\
\text { evaluation }\end{array}$ & $\begin{array}{c}\text { Lack of method } \\
\text { for EA } \\
\text { evaluation } \\
\end{array}$ \\
\hline F., \& Tavana, M. (2012) [7] & $\checkmark$ & $\checkmark$ & & $\checkmark$ \\
\hline Javanbakht, M., et al (2009) [28] & $\checkmark$ & & & $\checkmark$ \\
\hline Lange, M., \& Mendling, J. (2011) [29] & $\checkmark$ & & $\checkmark$ & $\checkmark$ \\
\hline Ojo, A., at al (2012) [30] & & & $\checkmark$ & $\checkmark$ \\
\hline Iacob, M. E., at al (2012) [31] & & $\checkmark$ & & $\checkmark$ \\
\hline Aier, S., \& Schelp, J. (2010) [32] & & $\checkmark$ & & $\checkmark$ \\
\hline Van Steenbergen, M., \& Brinkkemper, S. (2010) [33] & & & $\checkmark$ & $\checkmark$ \\
\hline Nakakawa, at al (2009) [34] & & $\checkmark$ & & $\checkmark$ \\
\hline Van Der Raadt, at al (2008) [35] & $\checkmark$ & $\checkmark$ & $\checkmark$ & $\checkmark$ \\
\hline Niemi, E., \& Ylimäki, T. (2008) [36] & & & & $\checkmark$ \\
\hline Weiss, S., at al (2013) [8] & $\checkmark$ & & & $\checkmark$ \\
\hline Pruijt, L., at al [24] & & & & $\checkmark$ \\
\hline
\end{tabular}

\section{DISCUSSION}

There are many existing evaluation methods and approaches in practice. Unfortunately, many models are not based on any theoretical foundations and lack good practices to accompany the proposed methods. These shortcomings lead to insufficient and inaccurate analysis of EA artefacts. Thus, the enterprise will not achieve the intended goal of the EA project. For more effective evaluation approach, comprehensive consideration should be given for requirement analysis in terms of functionality and effectiveness.

Evaluation model should support the EA project lifecycle including the design, management (development), and maintenanceThere is also a lack of consideration regarding consistency between evaluation's aspects in existing evaluation models. Consequently, the evaluation starts with using one approach, followed by other approaches that are not linked together. Besides, there is no specific practice for evaluating the functionality and effectiveness used by existing evaluation models. A usable evaluation model should focus on providing plan for evaluating the effectiveness and functionality of implemented EA artefacts.

Monitoring and governing are the critical parts of EA implementation maintenance, and evaluation approach should provide appropriate plan for supporting these activities for each EA project. By doing so, the evaluation model assists architects and stakeholders to continuously improve the EA implementation and increase the quality of intended EA implementation goals.

Effectiveness in EA refers to the ability of implemented EA on achievement of intended EA goals and provide appropriate integrated environment for developing EA artefacts. EA functionality describes how different components of enterprises, such as organizational units, business processes, people, and ISs, are related to each other and work as a whole towards the achievement of enterprise goals. Effective and usable EA evaluation method should consider effectiveness and functionality and use structured plan for evaluation. By doing this, effective EA evaluation method will enable to provide appropriate plans for governance and integration on developing accurate EA artefacts.

\section{CONCLUSION}

This paper has identified crucial issues of existing EA evaluation models. The investigation on EA evaluation literature carried out in this study provides a better insight of the current issues. By exploring the existing evaluation models, it was realized that there is no comprehensive and structured model and method in general for EA evaluation and specifically there is lack of focus towards assessing the functionality and the effectiveness of the EA artifacts.

The findings of the study may provide impetus for further work in this area including the need for more post-implemented EA approaches. In addition, the findings emphasize the relevance of effective and usable evaluation method due to its impacts on an enterprise performance. With effective EA evaluation method will surely provide leverage to the enterprises as well as generate constructive values for them towards achieving their goals. The results of this research would be extremely beneficial for academics, practitioners, and enterprise's decision makers in implementing and evaluating EA projects.

\section{REFERENCES}

[1] S. Aier, "The role of organizational culture for grounding, management, guidance and effectiveness of enterprise architecture principles," Inf. Syst. E-bus. Manag., 2014

[2] B. D. Rouhani, et al., "A systematic literature review on Enterprise Architecture Implementation Methodologies," Information and Software Technology, vol. 62, pp. 1-20, 2015. 
[3] G. Plataniotis, et al., "Capturing decision making strategies in enterprise architecture-A viewpoint," Enterprise, Business-Process and Information Systems Modeling, Springer, pp. 339-353, 2013.

[4] E. Niemi and S. Pekkola, "Enterprise Architecture Quality Attributes: A Case Study," 46th Hawaii International Conference on System Sciences, pp. 3878-3887, 2013.

[5] S. A. Bernard, "An Introduction to Enterprise Architecture," Third Edition, AuthorHouse, 2012.

[6] R. E. Giachetti, "A Flexible Approach to Realize an Enterprise Architecture," Procedia Comput. Sci., vol. 8, pp. 147-152, 2012.

[7] F. Zandi and M. Tavana, "A fuzzy group multi-criteria enterprise architecture framework selection model," Expert Syst. Appl., 2012.

[8] I. K. Raharjana, et al., "Information Technology Supplier Management in Hospitals," Bulletin of Electrical Engineering and Informatics, vol. 7, pp. 306-313, 2018.

[9] S. K. Pandey, "A comparative study of risk assessment methodologies for information systems," Bulletin of Electrical Engineering and Informatics, vol. 1, pp. 111-122, 2012.

[10] I M. Sukarsa, et al., "A New Framework for Information System Development on Instant Messaging for Low Cost Solution,” vol. 16, pp. 2799-2808, 2018.

[11] M. Osterlind, et al., "Enterprise architecture evaluation using utility theory," Enterprise Distributed Object Computing Conference Workshops (EDOCW), 2013 17th IEEE International, pp. 347-351, 2013.

[12] H. Plessius, et al., "On the categorization and measurability of enterprise architecture benefits with the enterprise architecture value framework," Trends in Enterprise Architecture Research and Practice-Driven Research on Enterprise Transformation. Springer Berlin Heidelberg, pp. 79-92, 2012.

[13] M. Karimi, et al., "A New Approach Based on Genetic Algorithm for Prioritizing Quality Scenarios in Enterprise Architecture Evaluation."

[14] L. Pruijt, et al., "The EARScorecard-An Instrument to Assess the Effectiveness of the EA Realization Process," Journal of Enterprise Architecture, vol. 09, pp. 20-3, 2013.

[15] P. Andersen and A. Carugati, "Enterprise Architecture Evaluation: A Systematic Literature Review," 2014.

[16] N. Baliyan and S. Kumar, "Software Process and Quality Evaluation for Semantic Web Applications," IETE Technical Review, vol. 31, pp. 452-462, 2014.

[17] J. Venable, et al., "A comprehensive framework for evaluation in design science research," International Conference on Design Science Research in Information Systems, Springer Berlin Heidelberg, pp. 423-438, 2012.

[18] B. Kitchenham, "Guidelines for performing systematic literature reviews in software engineering," 2007.

[19] B. Van der Raadt, et al., "The relation between EA effectiveness and stakeholder satisfaction," Journal of Systems and Software, vol. 83, pp. 1954-1969, 2010.

[20] J. Lakhrouit and K. Baina, "State of the art of the maturity models to an evaluation of the enterprise architecture," 2013 3rd International Symposium ISKO-Maghreb, pp. 1-8, 2013.

[21] M. Wissotzki and H. Koc, "A Project Driven Approach for Enhanced Maturity Model Development for EAM Capability Evaluation," 2013 17th IEEE International Enterprise Distributed Object Computing Conference Workshops, pp. 296-304, 2013.

[22] J. Löhe and C. Legner, "Overcoming implementation challenges in enterprise architecture management: a design theory for architecture-driven IT Management (ADRIMA)," Inf. Syst. E-bus. Manag., vol. 12, pp. 101-137, 2013.

[23] M. E. Iacob, et al., "From enterprise architecture to business models and back," Software \& Systems Modeling, vol. 13, pp. 1059-1083, 2014.

[24] L. Pruijt, et al., "The enterprise architecture realization scorecard: a result oriented assessment instrument," Trends in Enterprise Architecture Research and Practice-Driven Research on Enterprise Transformation, Springer Berlin Heidelberg, pp. 300-318, 2012.

[25] M. Janssen and B. Klievink, "Can enterprise architectures reduce failure in development projects?" Transforming Government: People, Process and Policy, vol. 6, pp. 27-40, 2012.

[26] C. Schmidt and P. Buxmann, "Outcomes and success factors of enterprise IT architecture management: empirical insight from the international financial services industry," Eur. J. Inf. Syst., vol. 20, pp. 168-185, 2010.

[27] F. Nikpay, et al., "Current Issues on Enterprise Architecture Implementation Evaluation," World Academy of Science, Engineering and Technology, International Journal of Social, Behavioral, Educational, Economic, Business and Industrial Engineering, vol. 9, pp. 112-115.

[28] M. Javanbakht, et al., "A new method for enterprise architecture assessment and decision-making about improvement or redesign," Computing in the Global Information Technology, 2009. ICCGI'09. Fourth International Multi-Conference on, pp. 69-76, 2009.

[29] M. Lange and J. Mendling, "An experts' perspective on enterprise architecture goals, framework adoption and benefit assessment," IEEE 15th International Enterprise Distributed Object Computing Conference Workshops, pp. 304-313, 2011.

[30] A. Ojo, et al., "Improving Government Enterprise Architecture Practice--Maturity Factor Analysis," System Science (HICSS), 2012 45th Hawaii International Conference on, pp. 4260-4269, 2012.

[31] M. E. Iacob, et al., "Capturing business strategy and value in enterprise architecture to support portfolio valuation," Enterprise Distributed Object Computing Conference (EDOC), 2012 IEEE 16th International, pp. 11-20, 2012.

[32] S. Aier and J. Schelp, "A reassessment of enterprise architecture implementation," Service-Oriented Computing. ICSOC/ServiceWave 2009 Workshops. Springer Berlin Heidelberg, 2010.

[33] M. van Steenbergen and S. Brinkkemper, "Modeling the contribution of enterprise architecture practice to the achievement of business goals," Inf. Syst. Dev., 2010. 
[34] A. Nakakawa, et al., "Quality enhancement in creating enterprise architecture: relevance of academic models in practice," Working Conference on Practice-Driven Research on Enterprise Transformation. Springer Berlin Heidelberg, 2009.

[35] B. Van Der Raadt, et al., "Stakeholder perception of enterprise architecture," European Conference on Software Architecture, Springer Berlin Heidelberg, pp. 19-34, 2008.

[36] E. Niemi and T. Ylimäki, "Enterprise Architecture Evaluation Components," Evaluation of enterprise and software architectures: critical issues, metrics and practices, in E. Niemi, et al., (eds.), Jyväskylä: University of Jyväskylä, Information Technology Research Institute, 2008. 